\title{
DYNAMIC RESPONSE OF FLOATING WIND TURBINE UNDER CONSIDERATION OF DYNAMIC BEHAVIOR OF CATENARY MOORING-LINES
}

\author{
Shuangxi Guo \\ a. AVIC Composite Corporation LTD, National \\ Key Laboratory of Advanced Composites \\ Beijing 100095, China \\ b. Key Laboratory of Mechanics in Fluid Solid \\ Coupling System, Institute of Mechanics, \\ Chinese Academy of Sciences \\ Beijing 100190, China
}

\author{
Yilun Li \\ Sino-French Engineering School, Beijing \\ University of Aeronautics and Astronautics \\ Beijing 100191, China
}

Min Li

School of Aeronautics

Sciences and Engineering,

Beijing University of

Aeronautics and

Astronautics

Beijing 100191, China
Weimin Chen ${ }^{*}$

a. Key Laboratory of Mechanics in Fluid Solid Coupling System, Institute of Mechanics, Chinese Academy of Sciences

Beijing 100190, China

b. School of Engineering Science, University

of Chinese Academy of Sciences

Beijing 100049, China

wmchen@imech.ac.cn

\author{
Yiqin Fu \\ Key Laboratory of \\ Mechanics in Fluid Solid \\ Coupling System, \\ Institute of Mechanics, \\ Chinese Academy of \\ Sciences \\ Beijing 100190, China
}

\begin{abstract}
Recently, wind turbine has been developed from onshore area to offshore area because of more powerful available wind energy in ocean area and more distant and less harmful noise coming from turbine. As it is approaching toward deeper water depth, the dynamic response of the large floating wind turbine experiencing various environmental loads becomes more challenge. For examples, as the structural size gets larger, the dynamic interaction between the flexible bodies such as blades, tower and catenary mooring-lines become more profound, and the dynamic behaviors such as structural inertia and hydrodynamic force of the mooring-line get more obvious. In this paper, the dynamic response of a $5 \mathrm{MW}$ floating wind turbine undergoing different ocean waves is examined by our FEM approach in which the dynamic behaviors of the catenary
\end{abstract}

${ }^{*}$ Corresponding author, Email: wmchen@imech.ac.cn mooring-line are involved and the integrated system including flexible multi-bodies such as blades, tower, spar platform and catenaries can be considered.

Firstly, the nonlinear dynamic model of the integrated wind turbine is developed. Different from the traditional static restoring force, the dynamic restoring force is analyzed based on our $3 d$ curved flexible beam approach where the structural curvature changes with its spatial position and the time in terms of vector equations. And, the modified finite element simulation is used to model a flexible and moving catenary of which the hydrodynamic load depending on the mooring-line's motion is considered. Then, the nonlinear dynamic governing equations is numerically solved by using Newmark-Beta method.

Based on our numerical simulations, the influences of the dynamic behaviors of the catenary mooring-line on its 
restoring performance are presented. The dynamic responses of the floating wind turbine, e.g. the displacement of the spar and top tower and the dynamic tension of the catenary, undergoing various ocean waves, are examined. The dynamic coupling between different spar motions, i.e. surge and pitch, are discussed too. Our numerical results show: the dynamic behaviors of mooring-line may significantly increase the top tension, particularly, the peak-trough tension gap of snap tension may be more than 9 times larger than the quasi-static result. When the wave frequency is much higher than the system, the dynamic effects of the mooring system will accelerate the decay of transient items of the dynamic response; when the wave frequency and the system frequency are close to each other, the displacement of the spar significantly reduces by around $26 \%$. Under regular wave condition, the coupling between the surge and pitch motions are not obvious; but under extreme condition, pitch motion may get about 20\% smaller than that without consideration of the coupling between the surge and pitch motions.

Key Words: dynamic response, floating wind turbine, catenary mooring-line, dynamic tension

\section{INTRODUCTION}

In recent years, more and more wind energy industries have been developing towards ocean area because of the advantages of ocean wind energy, e.g. higher wind speed, more steady wind field and lower level of noise to the onshore residents. Generally, the types of the floating wind turbines, mostly being used in ocean area and similar with the ocean oil/gas exploitation platform, include spar, tension-legged, semisubmerged, which needs to be positionally controlled or fixed in a certain range by its supporting/mooring system. And, compared with the fixed wind turbine onshore, the offshore environment loads comes from not only the wind but also ocean current and wave. Therefore the dynamic response of floating wind turbine undergoing various environmental loads is more complicated. Thus it is pretty challenging to analyze the dynamic response of the integrated system including top-end floating body and submarine mooring system and to consider the coupling between the flexible parts such as the tower and blade owing to significant flexibility of large-size wind turbine with more powerful efficiency.

To analyze the dynamic response of a floating wind turbine, the quasi-static method is mostly used where the mooring-line is regarded as static spring and then principally the statically restoring force is considered only, in other words, the dynamic behaviors such as the structural inertia and damping forces along with hydrodynamic forces of the mooring-line are not involved. Robertson[1] modeled mooring-line as nonlinear spring and examined the external loads and stability of wind turbine with different supporting systems. Karimirad[2] used the given relationship of the static restoring force versus the displacement and build a FEM model including blade and tower to study the dynamic response of a Spar wind turbine. Fischer[3] analyzed the dynamic characteristics of a TLP wind turbine and found that in harsh sea conditions the blade root stress and tower root bending stress become larger by $13 \%$ and $25 \%$ respectively by employing FAST[4-6] which originally was developed for fixed wind turbine by NREL (National Renewable Energy Laboratory) and then was modified to floating ones offshore, where finite degrees of freedom of wind turbine and quasi-static method mooring-line is considered.

As the water depth and consequently the structural length of the mooring-line get larger, the dynamic behavior such as inertia and damping forces along with hydrodynamic forces of the mooring-line becomes more remarkable[7,8]. It is found that the quasi-static method may overestimate the response of the wind turbine with catenary mooring-lines[7,9-11]. Based on the lumped-mass model, there were fruitful researches. For examples, Palm[12] analyzed the snap load and compared the dynamic results with the experiments; Masciola[9] studied the influences of inertia and hydrodynamic forces of mooringline on top tension and floating body response, he pointed out that for the semi-submersible wind turbine the dynamic effects on its sway and heave motions is limited but the top tension can be increased significantly; Hall[10] investigated the top tension under various load conditions and the calculation accuracies depending on mesh number, it was found that the mooring tension, particularly the fatigue load, may be under-estimated and $30 \%$ error may be caused by quasi-static method[11]. Matha[13] pointed out that the fluid force of the mooring-line would considerably change the dynamic response, especially the displacement of the floating body. Additionally, by FEM simulations, Skaare [14] and Larsen [15] considered the dynamic behavior of mooringline during analysis of dynamic response of wind turbine; Kallesoe[16] found that the fatigue loads may decrease if the dynamic behavior of the mooring-line is involved.

As for the structural model of wind turbine, two methods, i.e. the multi-body method and multi-degree of freedom method, are frequently used. Jeon[17] simplified the top nacelle and blades as a lumped mass, then he analyzed the response of a spar wind turbine moored by catenaries under irregular waves and examined the top tensions under different length and mooring-positions of the catenary. Christiansen[18] considered the wind load as a horizontal centered force at tower top and gave the six rigid-body motions of a floating body under actions of wind and wave. Stewart[19] used multi-degree-of-freedom model to study the dynamic response of a TLP wind turbine. Actually, these two methods regard the flexible bodies (such like flexible blade or tower) as either lumped-mass or multidegree-of-freedom body so as to somewhat simplify the structural model and, even sometimes, not to involve the interaction between the flexible bodies.

In this study, based on our numerical simulations by employing the finite element method which can consider the flexible bodies and their interaction, the dynamic response of a spar wind turbine, an integrated system including blades, tower, floating body and catenary mooring-lines, are examined. And 
particularly, the dynamic behaviors of the catenary mooringlines and its impacts on the integrated system response and catenary restoring performance under different wave conditions are studied.

\section{THE NUMERICAL SIMULATION MODEL}

\subsection{Governing Equations of a Catenary Considering Its} Dynamic Behavior

According to the classical static catenary theory which is frequently used, the top tension (static restoring force), essentially depending on structural gravity and overall spatial curve, can be given by solving the static equations. In other words, only the static restoring force of the mooring-line is considered. Here, in order to include structural inertial and damping, fluid drag forces and nonlinear geometry, we develop the dynamic governing equations. In this case, the dynamic restoring force can be obtained based on our $3 \mathrm{~d}$ curved flexible beam equations, in terms of vector expressions, where the structural curvature changes with its spatial position and time. For a $3 \mathrm{~d}$ catenary (see Fig.1), compared with the previous $2 \mathrm{~d}$ static model, the dynamic equations includes some nonlinear terms, that introduce the solution of dynamic response strong nonlinearity but is more reasonable for a moving catenary[2023]. Its governing equations of dynamics, in terms of vectors, can be written as[24,25]

$$
\begin{gathered}
\vec{F}^{\prime}+\vec{q}=\rho A \ddot{\vec{r}} \\
\vec{M}^{\prime}+\vec{r}^{\prime} \times \vec{F}+\vec{m}=0
\end{gathered}
$$

where $\boldsymbol{F}$ and $\boldsymbol{M}$ are respectively the total force and moment of the catenary. $\boldsymbol{q}$ and $\boldsymbol{m}$ are respectively the external force and moment acted on per unit length of the catenary. $\rho$ and $\boldsymbol{A}$ are structural mass density and section area respectively. $\boldsymbol{r}$ represents the position vector.

Then the expression of the bending moment and curvature is:

$$
\vec{M}=\vec{r}^{\prime} \times\left(B \vec{r}^{\prime \prime}\right)+H \vec{r}^{\prime}
$$

where $\boldsymbol{B}$ is the structural stiffness and $\boldsymbol{H}$ is the torsion moment. Substituting Eq.(3) into (2) yields:

$$
\vec{r}^{\prime} \times\left[\left(B \vec{r}^{\prime \prime}\right)^{\prime}+\vec{F}\right]+H^{\prime} \vec{r}^{\prime}+H \vec{r}^{\prime \prime}+\vec{m}=0
$$

and:

$$
H^{\prime}+\vec{m} \vec{r}^{\prime}=0
$$

where $\vec{m}$ is the average rotation moment having a value of zero if $\vec{m} \vec{r}=0$, then $\boldsymbol{H}=0$, that means the rotation moment is independent on the structural arc length. Generally, the rotation moment can be neglected, or the values of both $\boldsymbol{H}$ and $\vec{m}$ are zero. Then Eq.(4) can be rewritten as:

$$
\vec{r}^{\prime} \times\left[\left(B \vec{r}^{\prime \prime}\right)^{\prime}+\vec{F}\right]=0
$$

or:

$$
\vec{F}=-\left(B \vec{r}^{\prime \prime}\right)^{\prime}+\lambda \vec{r}^{\prime}
$$

Substituting Eq. (7) into (1) yields:

$$
-\left(B \vec{r}^{\prime \prime}\right)^{\prime \prime}+\left(\lambda \vec{r}^{\prime}\right)^{\prime}+\vec{q}=\rho A \ddot{\vec{r}}
$$

and the deformation equation is:

$$
\vec{r}^{\prime} \cdot \vec{r}^{\prime}=(1+\varepsilon)^{2}
$$

where $\varepsilon$ is the catenary strain. If the value of the bending moment in Eq.(7) is zero, we will have the dynamic equation of a flexible catenary of which the loads include the gravity, buoyancy and hydrodynamic forces.

The hydrodynamic force acted on per unit structure length can be expressed by the Morison formula as:

$$
f=\frac{1}{2} C_{D} \rho D|V-\dot{u}|(V-\dot{u})+\mathrm{C}_{A} \frac{\pi D^{2}}{4} \rho(\dot{V}-\ddot{u})+\frac{\pi D^{2}}{4} \rho \dot{V}
$$

where $D$ and $u$ are the structural diameter and displacement respectively. $V$ is the fluid velocity. Combing Eqs.(8), (9) and (10), now we have a nonlinear equation group of which direct solution could not be gotten theoretically. Here, a FEM numerical simulation is used to solve the dynamic equations.

The catenary is uniformly divided into $N$ elements which are two-node Euler beam element. For representativeness and simplicity, only the translation displacement in $\boldsymbol{x}-\boldsymbol{y}$ plane $\left[u_{i}, v_{i}\right]$, $\boldsymbol{i}=1,2, \ldots, N+1\left(\boldsymbol{N}+1\right.$ is the total number of nodes, and $u_{i}, v_{i}$ indicate the translation displacement in directions along with the $\boldsymbol{x}, \boldsymbol{y}$ axes respectively) and one rotation around $\boldsymbol{z}$ axis $\theta_{i}$, $i=1,2, \ldots, N+1$, of per node, are considered. The three-order polynomial function is used as the displacement expression of the beam element. Then the governing equation of the structure with many degrees of freedom can be written as follow:

$$
(M+\bar{M}) \ddot{U}+C \dot{U}+K U=F
$$

where $\boldsymbol{M}$ and $\bar{M}$ are respectively the structure mass matrix and the added mass matrix. $\boldsymbol{C}$ is the structure damping matrix. $\boldsymbol{K}$ is the stiffness matrix. $\boldsymbol{F}$ is the hydrodynamic force acted by ambient fluid. $U$ is the displacement vector. For a catenary body, in order to model simultaneously its original catenate shape and the large rotation/translation flexibilities of a vibrating catenary under consideration of its dynamic behavior, in our modified finite element simulations, the rotation motion between two neighboring beam elements is released, or the rotation angles of the two beam elements are no longer consistent with each other at same grid. And, the bending stiffness of every individual element is set to be zero. Subsequently, the system rotational degrees of the freedom $\theta$ would double as $\theta, \theta^{\prime}$ because of the additional rotation angle. The displacement vector of beam element changes from the original form

$$
U_{i}=\left[u_{i}, v_{i}, w_{i}, \theta_{i}, u_{i+1}, v_{i+1}, w_{i+1}, \theta_{i+1}\right]^{T}
$$

as:

$$
U_{i}^{\prime}=\left[u_{i}, v_{i}, w_{i}, \theta_{i}, \theta_{i}^{\prime}, u_{i+1}, v_{i+1}, w_{i+1}, \theta_{i+1}, \theta_{i+1}^{\prime}\right]^{T}
$$

Then, the additional constrains, or the original conditions, are required to obtain a certain solution of the dynamic equation, because of the statically indeterminate characteristics along with the stronger stiffness singularity of the system. Here the statically original shape and top tension based on traditional static catenary theory is used as the definite conditions of the 
dynamic mooring-line so as to eliminate the singularity of the stiffness matrix, or to constrain the system to a proper initial situation which is close to a practical catenary mooring-line.

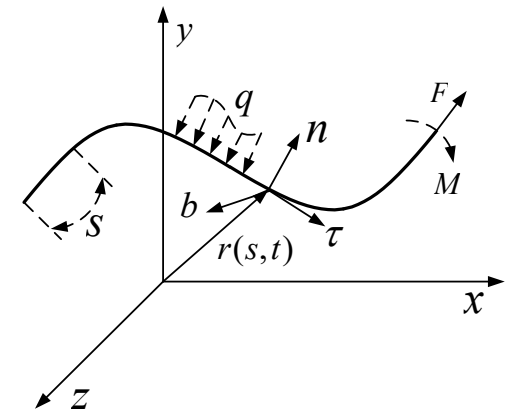

(a)

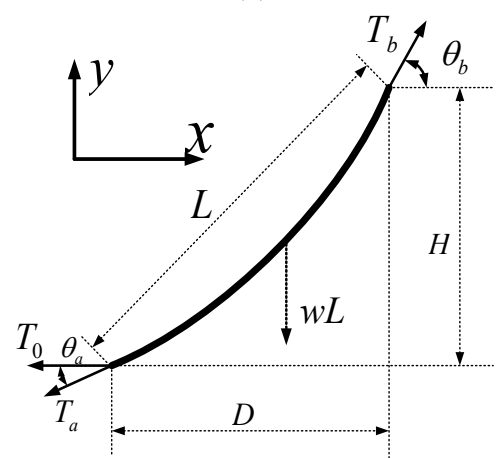

(b)

FIGURE 1. CATENARY MOORING LINE (a) THE SCHEMATIC DIAGRAM OF A 3D FLEXIBLE MOORING-LINE (b) THE TRADITIONAL STATIC FORCE BALANCE OF A CATENARY

\subsection{Governing Equations of the Integrated System and} Its Dynamic Response Based on FEM

For the integrated system including the blade and nacelle, tower, spar floating body and mooring-lines, the dynamic equation indicates the balance of the forces including the structural inertial and damping forces, dynamic restoring force coming from mooring-line and the environmental load (wind and hydrodynamic forces). It can be written as:

$$
M_{i j}(U, t) \ddot{U}_{j}+C_{i j}^{s t r}(U, t) \dot{U}_{j}+K_{i j}(U, t) U_{j}=F_{i}(U, \dot{U}, \ddot{U}, t)
$$

where $M_{i j}$ is the mass matrix and $\boldsymbol{U}_{\boldsymbol{j}}$ is the displacement. $\boldsymbol{t}$ is the time. $\boldsymbol{K}$ and $C_{i j}^{s t r}$ are the structural stiffness and damping matrices respectively. $\boldsymbol{F}_{\boldsymbol{i}}$ is the external load including the fluid force and restoring force of the mooring-lines. If only the rigid body motions are considered, the subscripts $i, j=1-6$ (respectively indicates the three translation motions and three rotational motions).

The external load acting on the floating body is:

$$
F_{i}=-A_{i j} \ddot{U}_{j}+F_{i}^{\text {Hydro }}+F_{i}^{\text {Lines }}
$$

where $A_{i j}$ is the added-mass matrix. $F_{i}^{\text {Lines }}$ is the dynamic restoring force coming from the moving mooring-lines.

The hydrodynamic force $F_{i}^{\text {Hydro }}$ includes:

$$
F_{i}^{\text {Hydro }}=F_{i}^{\text {Wave }}+\rho_{1} g V_{0} \delta_{i 3}-C_{i j}^{\text {Hydro }} U_{i j}
$$

where the wave force $F_{i}^{\text {Wave }}$ can be get by the traditional potential theory, or by the Morison equation expressed as Eq. (10) when the structural diameter is much smaller than the wave length. For the spar floating body in this paper the Morison eq. is used and the drag coefficient is $0.6[26]$. The second term $\rho_{1} g V_{0} \delta_{i 3}$ is the static fluid buoyancy where $\rho_{1}$ and $g$ are the fluid density and gravity acceleration respectively. $\boldsymbol{V}_{0}$ is the displaced volume, and $\delta_{i 3}$ indicates the unit vector in direction 3(it's in terms of "1,2,3") (heave motion). The third term $-C_{i j}^{H y d r o} U_{i j}$ is the restoring force due to the wet surface change and the center of buoyancy of the floating body, which has the coefficient matrix as:

$$
C_{i j}^{\text {Hydro }}=\left[\begin{array}{cccccc}
0 & 0 & 0 & 0 & 0 & 0 \\
0 & 0 & 0 & 0 & 0 & 0 \\
0 & 0 & C_{33} & 0 & C_{35} & 0 \\
0 & 0 & 0 & C_{44} & 0 & 0 \\
0 & 0 & C_{35} & 0 & C_{55} & 0 \\
0 & 0 & 0 & 0 & 0 & 0
\end{array}\right]
$$

Particularly here, the restoring force of the mooring-line $F_{i}^{\text {Lines }}$ actually includes two parts: one part is the traditional static tension due to the catenary original position and structure gravity; another part is the additional dynamic forces due to catenary motion and involves the damping force $-C_{i j}^{\text {Lines }} U_{j}$ and the inertia force $M_{i j}^{\text {Lines }} \ddot{U}_{j}$ as follow:

$$
F_{i}^{\text {Lines }}=F_{i}^{\text {Lines, } 0}-C_{i j}^{\text {Lines }} \dot{U}_{j}+M_{i j}^{\text {Lines }} \ddot{U}_{j}
$$

By now, the dynamic equation of an integrated system, i.e. multi-flexible-body system, including blades and nacelle, tower, floating body and mooring-lines is given as:

$$
\begin{aligned}
& {\left[\begin{array}{ccc}
M_{W} & M_{12} & M_{13} \\
M_{21} & M_{P} & M_{23} \\
M_{31} & M_{32} & M_{\text {moor }}
\end{array}\right]\left[\begin{array}{c}
\ddot{U}_{W} \\
\ddot{U}_{P} \\
\ddot{U}_{\text {moor }}
\end{array}\right]+\left[\begin{array}{lll}
C_{11} & C_{12} & C_{13} \\
C_{21} & C_{22} & C_{23} \\
C_{31} & C_{32} & C_{33}
\end{array}\right]\left[\begin{array}{c}
\dot{U}_{W} \\
\dot{U}_{P} \\
\dot{U}_{\text {moor }}
\end{array}\right]} \\
& +\left[\begin{array}{lll}
K_{11} & K_{12} & K_{13} \\
K_{21} & K_{22} & K_{23} \\
K_{31} & K_{32} & K_{33}
\end{array}\right]\left[\begin{array}{c}
U_{W} \\
U_{P} \\
U_{\text {moor }}
\end{array}\right]=\left[\begin{array}{c}
F_{W} \\
F_{P} \\
F_{\text {moor }}
\end{array}\right]
\end{aligned}
$$

where $U_{W T}$ is the displacement vector including the blade, nacelle and tower displacements, $U_{\text {spar }}$ and $U_{\text {moor }}$ are respectively the displacement vectors of the floating body and mooring-lines. The right side term, the system force, essentially involves the environmental loads (wind and wave forces), structural body forces (gravity force and centrifugal force of rotating blade) and the dynamic restoring force of the moving mooring-lines (with the effects of inertia and damping), and these forces are acted on various parts of the wind turbine and respectively involved into the three force sub-vectors, $F_{W T}, F_{s p a r}$ and $F_{\text {moor }}$. It is noted that the non-diagonal elements of the 
system matrices imply the mass/stiffness/damping interactions between different flexible bodies. And, the conforming elements are used to connect the rigid body and flexible body in our FEM model so that the calculation process would not be singular during the whole dynamic response.

To run the dynamic response analysis, a numerical simulation is used to solve the FEM dynamic equations. Among those direct numerical integration methods like the Newmark and the Finite Difference methods, the Newmark method is employed here so as to adjust the distribution of the structural acceleration and the nonlinearity of the catenary during the integration range by properly changing the integration parameters. The interpolation functions of the displacement and acceleration are written as:

$$
\begin{aligned}
& \dot{U}_{t+\Delta t}=\dot{U}_{t}+\left[(1-\beta) \ddot{U}_{t}+\beta \ddot{U}_{t+\Delta t}\right] \Delta t \\
& U_{t+\Delta t}=\dot{U}_{t}+\dot{U}_{t} \Delta t+\left[\left(\frac{1}{2}-\alpha\right) \ddot{U}_{t}+\alpha \ddot{U}_{t+\Delta t}\right] \Delta t^{2}
\end{aligned}
$$

where the values of $\alpha$ and $\beta$ are respectively $1 / 6$ and $1 / 2$ at every time step during the dynamic response.

\subsection{The Structural Parameters of the Wind Turbine} and the Dynamic Characteristics of the Integrated System

We take the OC3-Hywind spar wind turbine[26,27] as our example, where a 5MW turbine was assembled with a spar floating body moored by three catenaries, and its main structural parameters are listed in Table 1.

The six rigid body motions are usually used to measure the stability and dynamic response of wind turbine under wind and wave actions. Here particularly to a spar wind turbine, the horizontal motions like the surge and sway are principally dependent on the restoring performance of the mooring-line while the rest motions are mainly determined by the properties of floating body itself, e.g. the heave and pitch motions can be controlled by its own inertia. Given the appropriate heave stability, here we will discuss the surge and pitch motions.

\begin{tabular}{cc} 
TABLE 1. THE STRUCTURAL PARAMETERS OF OC3-HYWIND \\
SPAR WIND TURBINE \\
\hline Parameters & Value \\
\hline Tower Top Height above Ground & $87.6 \mathrm{~m}$ \\
Tower Density & $8500.0 \mathrm{~kg} / \mathrm{m} 3$ \\
Spar Draft & $120.0 \mathrm{~m}$ \\
Spar Gravity & $7466330 \mathrm{~kg}$ \\
Equivalent Mooring Line Weight in Water & $698.094 \mathrm{~N} / \mathrm{m}$ \\
Depth to Anchors Below Water & $420.0 \mathrm{~m}$ \\
Radius to Anchors from Platform Centerline & $706.0 \mathrm{~m}$ \\
Unstretched Mooring Line Length & $800.0 \mathrm{~m}$ \\
\hline
\end{tabular}

The FEM model of the integrated system, i.e. the multiflexible-body system including blades, nacelle, tower, floating body and mooring-lines, was built as shown in Fig. 2. In the FEM model, every single blade was divided into 123 Euler beam elements, and the tube tower and floating spar were divided respectively into 100 and 200 beam elements. The mooring-line was divided into the special beam elements between neighboring elements of which the rotation motion is released and bending stiffness of every individual element is set to be zero as mentioned in Section 2. Each mooring-line is divided into 200 elements, and the fluid drag force acted on the mooring-line is considered during the dynamic response. The wave force of the mooring-line can also be get by the Morison equation as Eq.(10); where the drag coefficient is 1.2[26].

The dynamic characteristics of the integrated system are calculated based on our FEM simulations and compared with the experimental results given in Ref.[20] so as to verify our FEM model, as shown in Table 2. Satisfied agreement between our numerical and the experimental results, i.e. less than $5 \%$ differences, is seen.

\section{TABLE 2. THE NATURAL PERIODS OF THE WIND TURBINE}

\begin{tabular}{cccc}
\hline Mode & Numerical Result/s & Ref.[20]/s & Difference \% \\
\hline Surge & 120.00 & 125.60 & 4.46 \\
Sway & 120.00 & 125.60 & 4.46 \\
Pitch & 28.00 & 28.50 & 1.75 \\
Roll & 27.70 & 28.50 & 2.81 \\
\hline
\end{tabular}

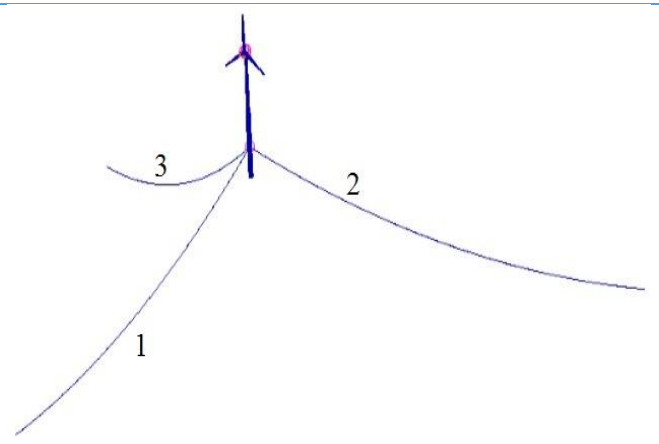

(a)

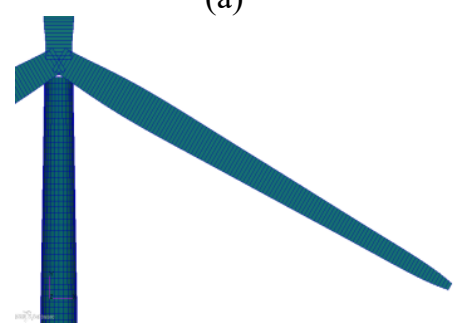

(b)

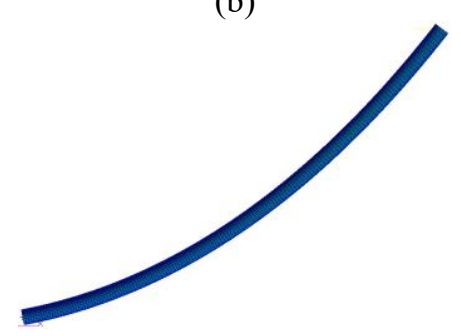

(c)

FIGURE 2. THE FEM MODEL of THE INTEGRATED SYSTEM INCLUDING THE BLADES, TOWER, FLOAGTING SPAR AND CATENARY MOORING-LINES (a) THE INTEGRATED SYSTEM (b) THE PARTIAL ENLARGED VIEW OF BLADES AND TOWER (c) THE PARTIAL ENLARGED VIEW OF A CATENARY MOORING-LINE 


\section{DYNAMIC RESTORING PERFORMANCE OF THE CATENARY AND RESPONSE OF THE INTEGRATED SYSTEM}

The 6 cases of the regular wave[21] considered for the dynamic response are listed in Table 3, and the initial condition of the dynamic response is the structural body being still. As a comparison, a quasi-static model of the mooring-line are also established so as to examine the impact of catenary dynamic behavior on the overall system response.

TABLE 3 CASES OF REGULAR WAVE

\begin{tabular}{ccc}
\hline Load Case & Wave Period $/ \mathrm{s}$ & Wave Height $/ \mathrm{m}$ \\
\hline 1 & 10 & 3 \\
2 & 12 & 3 \\
3 & 14 & 3 \\
4 & 16 & 3 \\
5 & 18 & 3 \\
6 & 20 & 3 \\
\hline
\end{tabular}

3.1 The Restoring Performance of the Catenary Mooring-Line under Consideration of Its Dynamic Behavior

The restoring tension and the influence of the dynamic behaviors will be discussed. The time history of the top tension of the catenary mooring-line 1 are presented in Figs. 3 and 4 (at 20 s wave period, $2 \mathrm{~m}$ and $3 \mathrm{~m}$ surge amplitudes respectively). In Fig. 3 no apparent difference between the quasi-static and dynamic tensions is seen at small surge amplitude, but in Fig.4 dynamic tension is $7 \%$ larger than the quasi-static value. Moreover, the results with lower wave period (or faster surge frequency) and larger surge amplitude are presented in Fig.5 and 6 where the wave period is $10 \mathrm{~s}$ and surge amplitudes are $2 \mathrm{~m}$ and $3 \mathrm{~m}$ respectively. Compared with Figs. 3 and 4, we note that as the frequency and/or amplitude of top-end surge motion get larger, the top tension gets much larger than the quasi-static value, e.g. at the $10 \mathrm{~s}$ period $3 \mathrm{~m}$ surge amplitude, the value of top tension increases form $1100 \mathrm{kN}$ (static value) to $1650 \mathrm{kN}$ (dynamic value), i.e. by $50 \%$, moreover the gap value between the peak and trough is around 5 times of the quasi-static one.

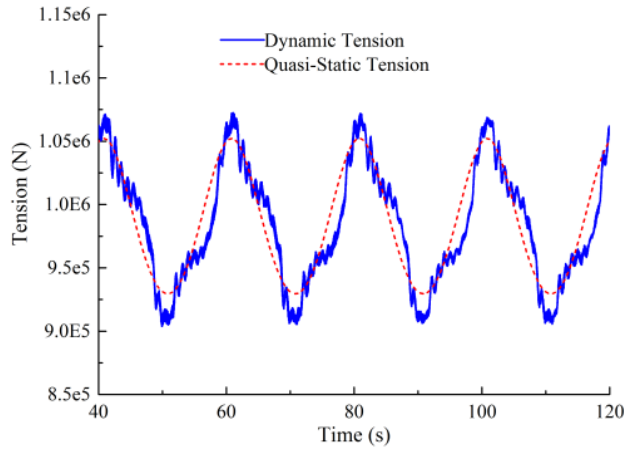

FIGURE 3. TOP TENSION OF THE CATENARY LINE (WITH SPAR SURGE AMPLITUDE $=2 \mathrm{~m}$, PERIOD $=20 \mathrm{~s}$ )

Particularly, it is noted that the slack-taut phenomenon (high snap load)of the catenary may happen during the dynamic response, e.g. at $0.1 \mathrm{~Hz}$ frequency and $6 \mathrm{~m}$ amplitude of top-end surge, see Fig.7. There is an abrupt decrease of the dynamic tension till to its minimum value-almost zero, and then the maximum tension rises to nearly 3 times of the quasi-static one owing to the dynamic behaviors of the catenary. If observing the plots of the velocity versus displacement of the catenary middle point, see Fig.8, the motion center of the horizontal displacement (Fig.8a) moves toward negatively to the point zero, and there is a little horizontal velocity fluctuation as the displacement changes from the negative value to positive one and to reach its maximum value. Moreover, Fig. $8 \mathrm{~b}$ indicates that the vertical velocity almost keeps constant, at its minimum value, as the displacement change from positive peak to negative trough. That means owing the additional dynamic behavior of the catenary, the structural initial/damping forces along with the fluid drag force can balance the structural gravity which is supposed to principally cause the structural tension, and consequently, slack would happen if no tension is caused.

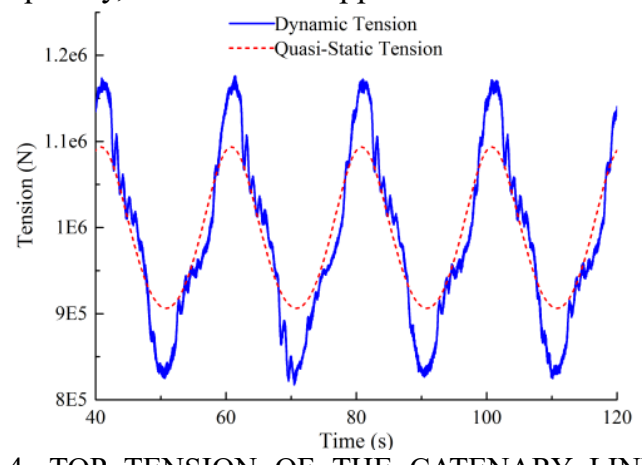

FIGURE 4. TOP TENSION OF THE CATENARY LINE (WITH SPAR SURGE AMPLITUDE $=3 \mathrm{~m}$, PERIOD $=20 \mathrm{~s}$ )

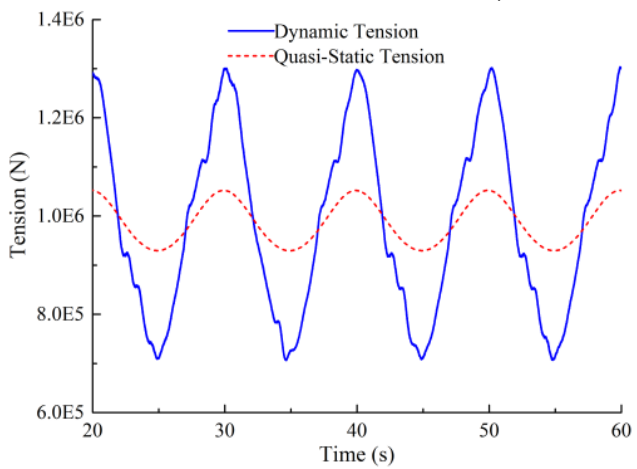

FIGURE 5. TOP TENSION OF THE CATENARY LINE (WITH SPAR SURGE AMPLITUDE $=2 \mathrm{~m}, \mathrm{PERIOD}=10 \mathrm{~s}$ )

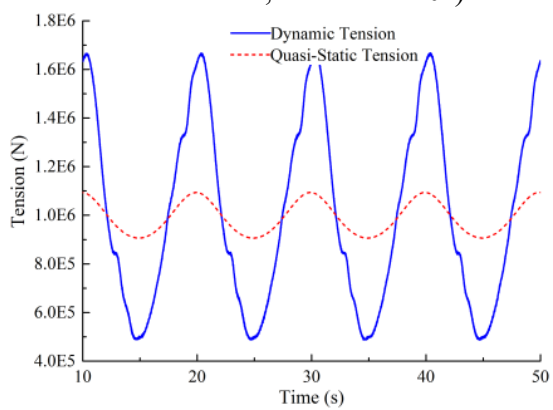

FIGURE 6. TOP TENSION OF THE CATENARY LINE (WITH SPAR SURGE AMPLITUDE $=3 \mathrm{~m}$, PERIOD $=10 \mathrm{~s}$ ) 


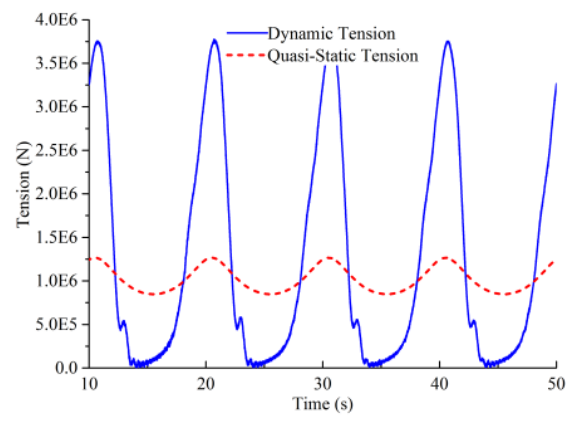

FIGURE 7. TOP TENSION OF THE CATENARY LINE (WITH SPAR SURGE AMPLITUDE $=6 \mathrm{~m}$, PERIOD $=10 \mathrm{~s}$ )

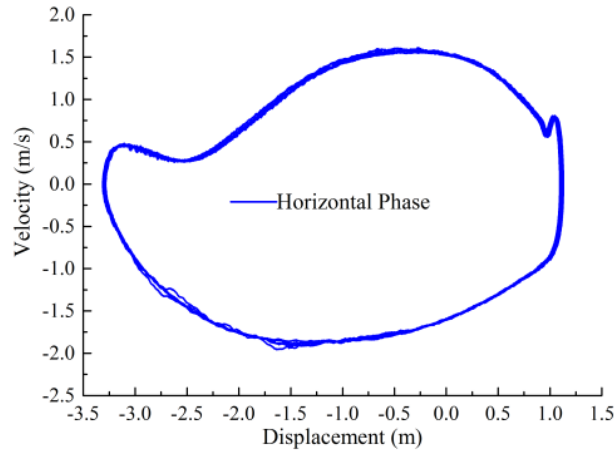

(a)

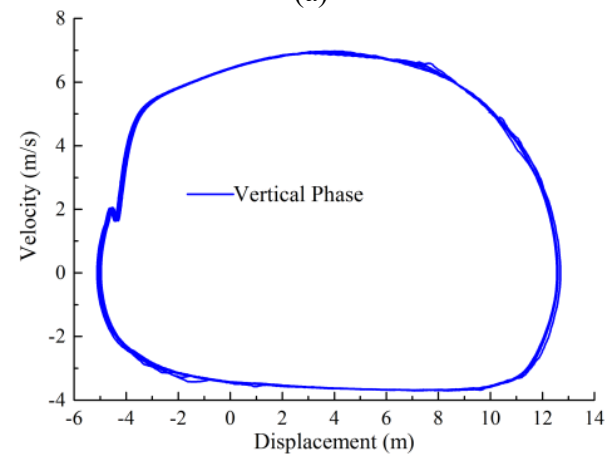

(b)

FIGURE 8. PHASE TRACK OF THE VELOCITY VERSUS DISPLACMENT OF THE MIDDLE POINT OF THE CATENARY LINE (a) THE TRACK OF HORIZONTAL MOTION (b) THE TRACK OF VERTICAL MOTION

In order to present the influence of fluid drag on the restoring performance of the catenary, the maximum tensions under consideration of fluid drag is plotted and compared with that without fluid drag (or in the air) in Fig. 9 (at $4 \mathrm{~m}$ surge amplitude). It is shown that as the surge frequency gets larger, the maximum tension with fluid drag gradually gets larger but it initially drops a little and then rises if without the fluid drag. And, the maximum tension for case of with fluid drag is larger than, up to twice of, that without fluid drag. The reason might be the suppression effect of the fluid drag to the catenary velocity, while if in the air the structural inertia force may partly counteract the body gravity and then consequently reduces the tension as shown in Fig.9.

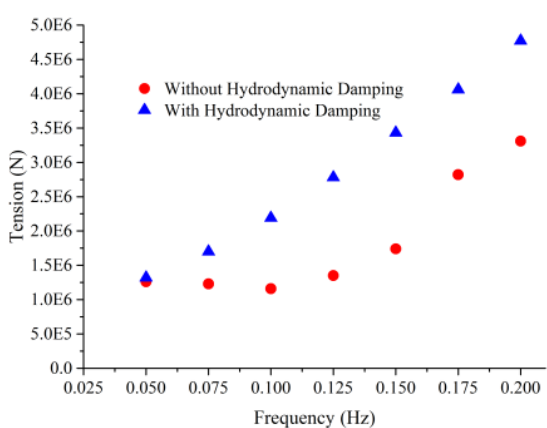

FIGURE 9. EFFECT OF HYDRODYNAMIC DRAG ON MOORING-LINE'S TENSION

\subsection{The Dynamic Responses of the Spar Floating Body and the Tower Top}

The displacement time history and frequency spectrum of the spar floating body are presented in Fig. 10 and 11, at 10s wave period and $3 \mathrm{~m}$ wave height. For case of surge, Fig.10a shows that the transient response of the floating body stays for a certain longer time and its amplitude is much higher than, up to 9 times of, the steady displacement. And the amplitude at the natural frequency $(0.0083 \mathrm{~Hz})$ is much larger than that at the excitation frequency $(0.10 \mathrm{~Hz})$, that means the transient response is, in some way, more dangerous and should be paid attention during structural safety assessment in practices. However, for case of pitch motion, the transient response of the floating body is less profound, see Fig.11, partly because the excitation frequency $(0.10 \mathrm{~Hz})$ is closer to the natural frequency $(0.037 \mathrm{~Hz})$, compared with the surge frequency $(0.0083 \mathrm{~Hz})$. In this case, the steady response becomes more significant than that of surge motion.

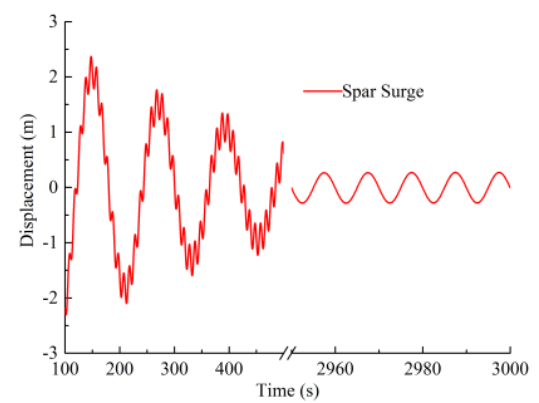

(a)

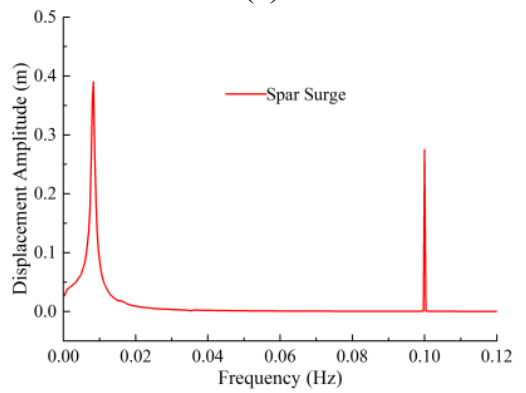

(b)

FIGURE 10. THE TIME HISTORY AND FREQUENCY SPECTRUM OF SPAR SURGE (a) THE TIME HISTORY OF SURGE DISPLACEMENT (b) THE FREQUENCY SPECTRUM 


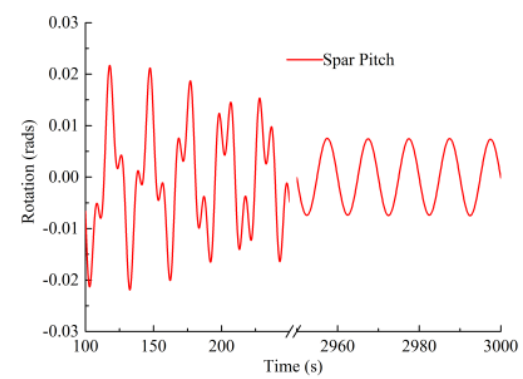

(a)

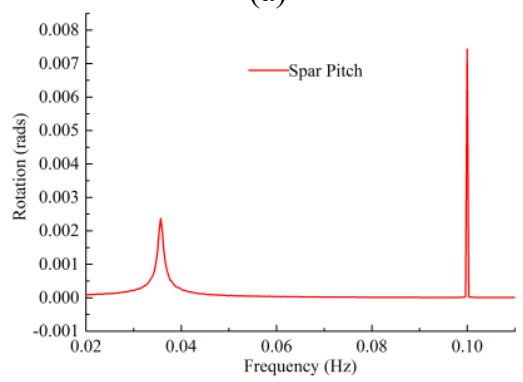

(b)

FIGURE 11. THE TIME HISTORY AND FREQUENCY SPECTRUM OF SPAR PITCH (a) THE TIME HISTORY OF PITCH DISPLACEMENT (b) THE FREQUENCY SPECTRUM

Concerning the response of tower top, Fig. 12 shows that the tower displacement is principally caused by both the surge and pitch motions of the floating body, and the pitch motion has more obvious influence on the tower top response. The time history of tower top displacement indicates the transient response is mainly dominated by the pitch motion, compared with the surge motion, the pitch causes a larger motion on the tower top due to the large tower height.

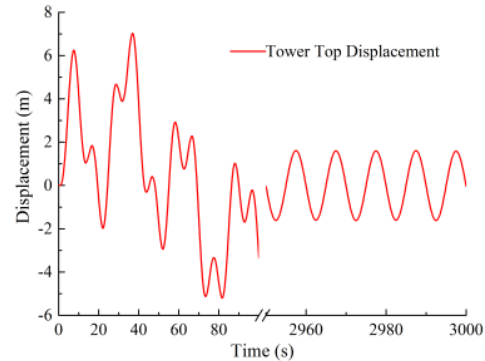

(a)

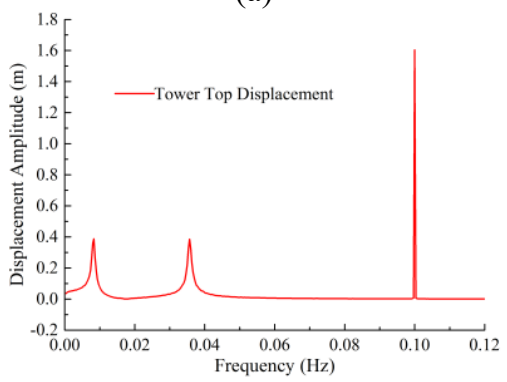

(b)

FIGURE 12. THE TIME HISTORY AND FREQUENCY SPECTRUM OF TOWER TOP DISPLACEMENT (a) THE DISPLACEMENT TIME HISTORY (b) THE FREQUENCY SPECTRUM
3.3 Impacts of Dynamic Behaviors of Catenary on the Wind Turbine System Response

Here two cases, i.e. Case 1 the wave frequency is much larger than the natural frequency of the wind turbine, called higher frequency excitation, and Case 2 the wave frequency is close to the natural frequency of the wind turbine, called lower frequency excitation, are considered. And as a comparison, the response based on quasi-static method is also presented to examine the impacts of dynamic behaviors of catenary on the wind turbine system response.

Firstly, for Case 1 and concerning the surge motion, Fig. 13 shows that as the wave frequency is much higher than the natural frequency of the wind turbine, there is no obvious differences between the dynamic and the quasi-static results, except that the dynamic transient response decreases by $11.4 \%$, or, in other words, dynamic behavior of the catenary overall has a small influence on the wind turbine system. And the steady response of the wind turbine is smaller than the transient response. Since during the phase of transient response, one component of the overall response has the frequency close to the wave frequency, then the inertia and damping forces along with the hydrodynamic forces can increase the restoring tension, which may cause the decrease of overall response of the system.

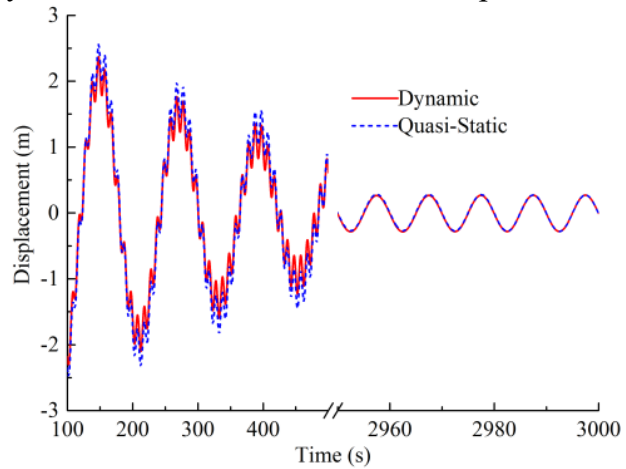

(a)

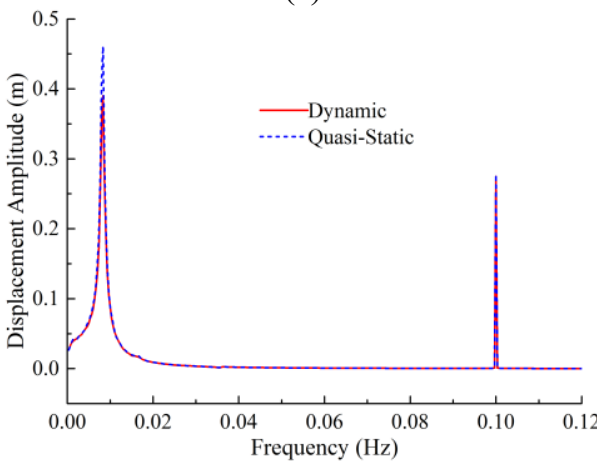

(b)

FIGURE 13. THE DYNAMIC RESPONSE OF SPAR SURGE UNDER WAVE WITH HIGHER FREQUENCY (a) THE TIME HISTORY INCLUDING TRANSIENT AND STEADY PHASES, OF SURGE DISPLACEMENT (b) THE FREQUENCY SPECTRUM

If concerning the pitch response, see Fig. 14, the displacement of the presented model is very close to the quasistatic results in both terms of the transient and steady responses. 
That is because of the unique stability performance of spar wind turbine itself. Specifically, for a spar floating body, the restoring force of mooring-lines mainly control the translation motions such as surge, sway and heave. As for the rotation motions like pitch and roll, is mainly controlled by the static fluid bouncy force and structural gravity/mass center rather than the catenary's restoring force.

However, for Case 2, or under condition of the wave frequency being close to the natural frequency of the wind turbine, Fig. 15 shows that the dynamic behavior of the catenary has a significant impact on the system response. For example, the surge displacement amplitude drops by $26 \%$, compared with the quasi-static result. If comparing the top tensions in Fig. 16, the maximum restoring force considering the dynamic behavior gets larger since the additional inertia and damping forces along with the hydrodynamic forces can make the structural tension rise. And interestingly, the dynamic stiffness curve shows that the catenary tension is no longer linearly related to only the body displacement as it does for case of quasi-static scenario, but, notably, it depends on both the body displacement and velocity approximately in a way of ellipse loop as shown in Fig.16. Or, the dynamic restoring force actually has a directional property mainly owing to the involvement of the dynamic behavior which principally depends on both the amplitude and direction of the body.

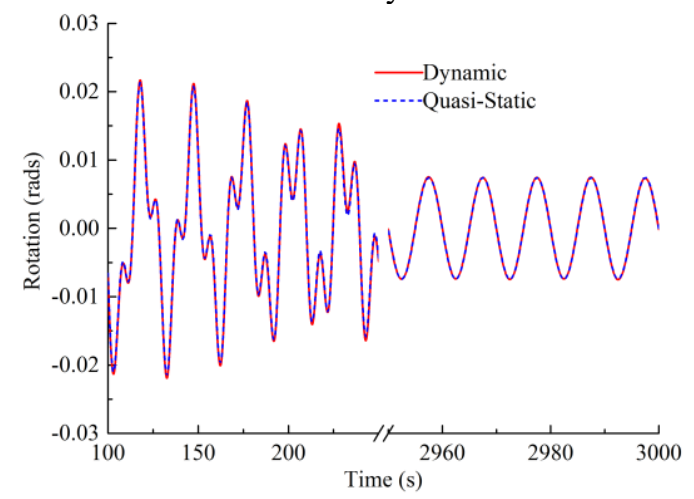

FIGURE 14. THE DYNAMIC RESPONSE OF SPAR PITCH UNDER WAVE WITH HIGHER FREQUENCY

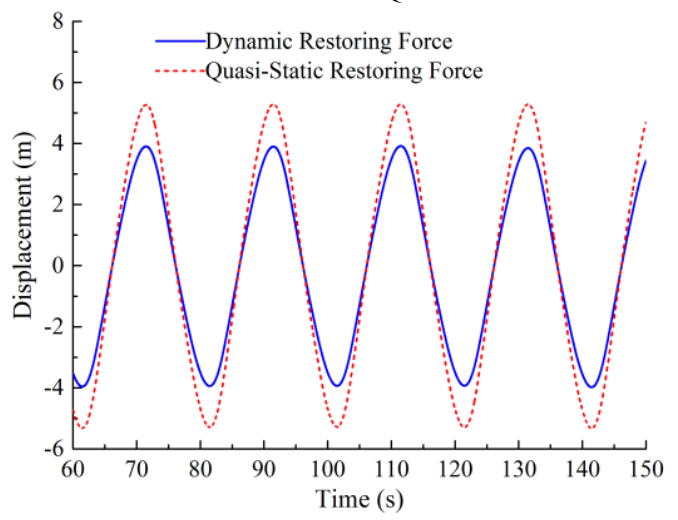

FIGURE 15. THE DYNAMIC RESPONSE, DURING STEADY PHASE, OF SPAR SURGE UNDER WAVE WITH LOWER FREQUENCY

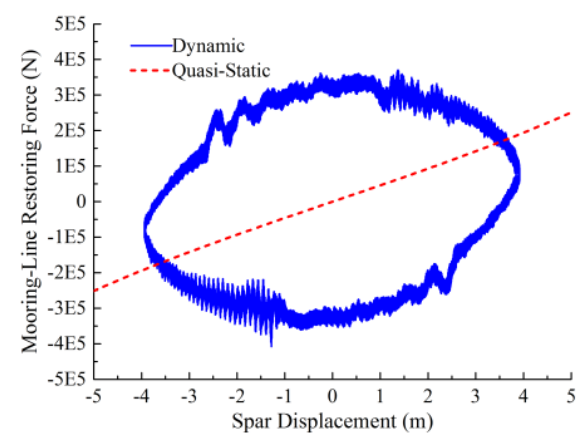

FIGURE 16. COMPARISON RESTORE FORCES BETWEEN THE DYNAMIC AND STATIC MOORING SYSTEM

\subsection{Coupling Response of Floating Body Motions}

Generally, to a spar floating wind turbine, the restoring force of the surge motion is principally provided by its mooring-lines while the restoring force moment of the pitch motion is principally provided by its own structural gravity and static fluid bouncy. Thus, for case of small displacement, different motions would not be coupled with each other. It means one can separately analyze every motion response, i.e. one can set only one motion free and constrain other motions during dynamic response analysis,. However, for case of nonlinear motion with larger amplitude under condition like high sea state, different things happen to the two motions, i.e. the surge and pitch.

Under condition of regular wave, the displacement (or rotation angle) time history of steady responses is plotted in Fig. 17 and 18 respectively for surge and pitch motions, where the single surge (or pitch) response means only this motion is set free and the rest of the motions are constrained, and, similarly, the coupling surge means both surge and pitch motions are set free during the dynamic response. Fig. 17 and 18 show that the motion, e.g. $1.8 \mathrm{~m}$ surge amplitude and $0.038 \mathrm{rad}$ pitch angle is small under regular wave and there is no obvious difference between the single and coupling surge responses. In other words, when the displacement is small, the six rigid body motions of floating body doesn't couple with each other, or there is no obvious interaction between different motions.

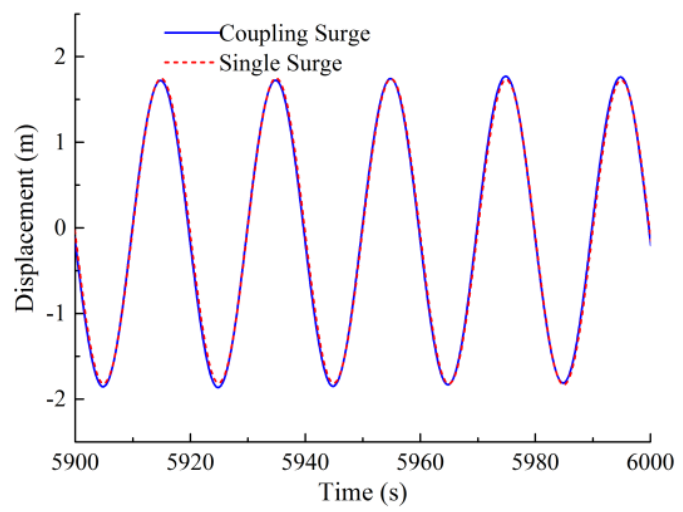

FIGURE 17. THE DYNAMIC RESPONSE OF SPAR SURGE UNDER NORMAL WAVE CONDITION 


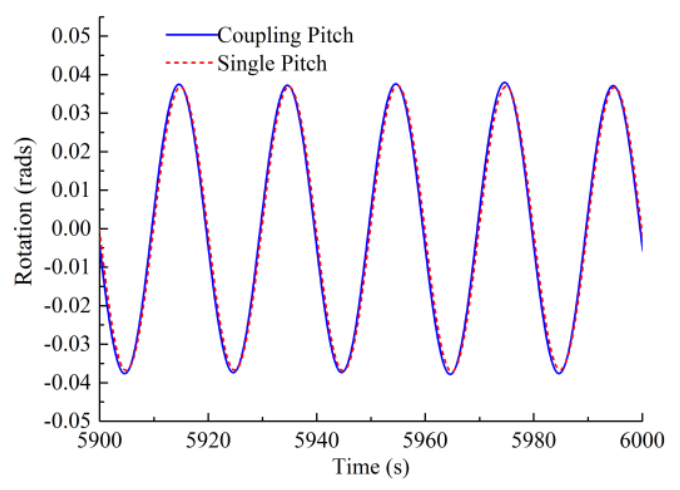

FIGURE 18. THE DYNAMIC RESPONSE OF SPAR PITCH UNDER NORMAL WAVE CONDITION

However, under harsh condition, i.e. $8 \mathrm{~m}$ wave height and 20s wave period, the displacement (or rotation angle) time history of steady responses, see Fig. 19 and 20, gets larger, e.g. from $1.8 \mathrm{~m}$ to $3.5 \mathrm{~m}$ surge amplitude and from $0.038 \mathrm{rad}$ to $0.076 \mathrm{rad}$ pitch angle, owing to increasing wave load. Observing Fig.19, there is a small amplitude fluctuation with long period during the steady response of single surge, though its average amplitude is almost the same with the coupling surge response.

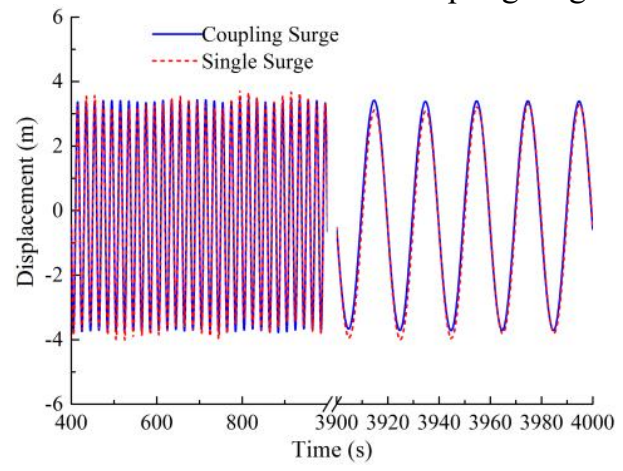

FIGURE 19. THE DYNAMIC RESPONSE OF SPAR SURGE UNDER HARSH WAVE CONDITION

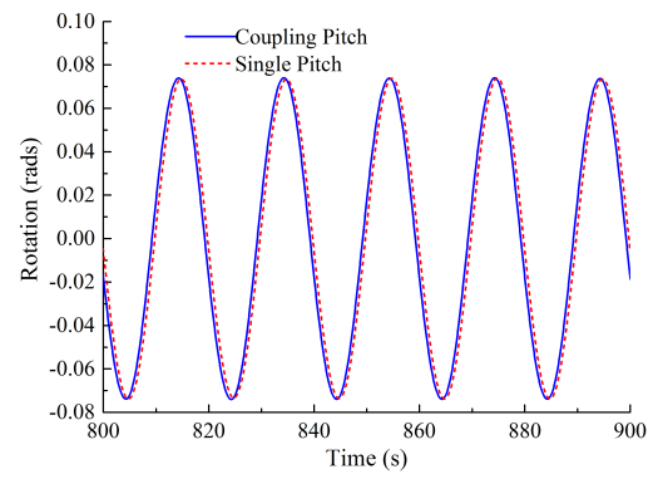

FIGURE 20. THE DYNAMIC RESPONSE OF SPAR PITCH UNDER HARSH WAVE CONDITION

Interestingly, if comparing the single and coupling pitch responses of longer time history, see Fig. 21 and 22, a beat with lower frequency can be seen with a $25.7 \%$ larger amplitude. That is to say as the spar floating body vibrates with larger amplitude under harsh condition, if the surge motion can be strictly controlled by its mooring-line, or the surge motion is very small, there may be beat vibration companying with a larger amplitude during the pitch motion. So, for a spar floating wind turbine, it is not always true that the larger the restoring stiffness is, the smaller the floating body motion is. Or, if the restoring stiffness of the surge motion is too large, the pitch motion may get larger, rather than getting small, under harsh condition.

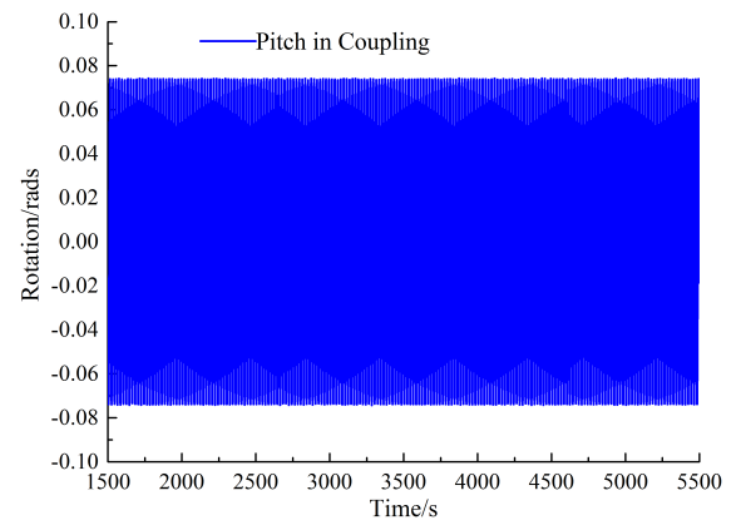

FIGURE 21. LONG PERIOD SPAR PITCH IN COUPLING UNDER HARSH WAVE CONDITION

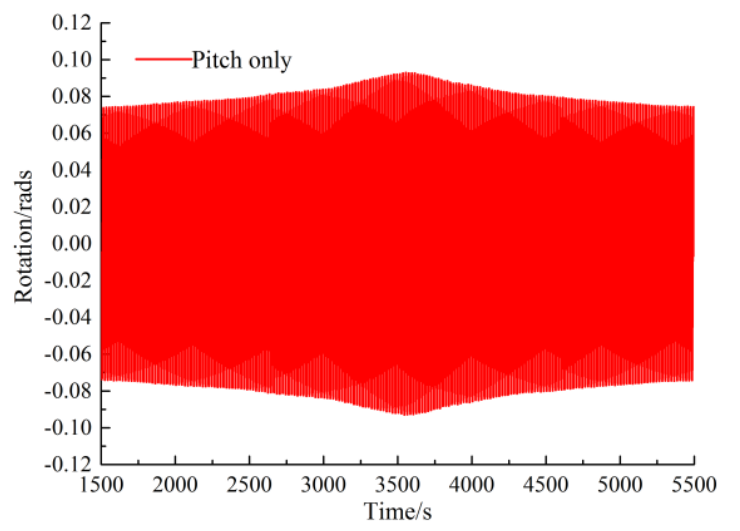

FIGURE 22. LONG PERIOD SPAR SINGLE PITCH UNDER HARSH WAVE CONDITION

\section{CONCLUSION}

The dynamic response of a floating wind turbine with large structural size undergoing different ocean waves is examined by our approach which combines the $3 \mathrm{~d}$ flexible catenary theory with the modified finite element method. By use of our approach, the dynamic behaviors, including the structural inertia and damping forces along with the fluid drag of flexible catenary mooring-line are involved; what's more, the integrated system which includes the flexible components such as blades, tower, spar platform and catenary mooring-lines can be considered during the dynamic response. Based on our numerical simulation, the influences of the dynamic behaviors of the catenary mooring-line on its restoring performance are presented. The dynamic responses of the floating wind turbine, e.g. the displacement of the spar/tower and the dynamic tension of the catenary, undergoing different ocean waves are examined. The dynamic coupling between different motions, i.e. surge and 
pitch, of the floating Spar are discussed too. Based on our numerical results, we draw the flowing conclusions:

1) The dynamic behaviors of mooring-line may significantly increase the maximum top tension. As the top floating body motion gets larger, the maximum tension gets larger too. Particularly, the peak-trough tension difference may be 9 times larger than the quasi-static result owing to the occurrence of slack-taut during the dynamic response.

2) When the wave frequency is much higher than the wind turbine system, the dynamic effects of the mooring-lines will accelerate the decay of transient items of the dynamic response, and the surge amplitude could decrease by $10 \%$; when the wave frequency is close to the wind turbine frequency, the dynamic effects of mooring-lines can significantly reduce, by around $26 \%$, the response displacement of the spar body.

3) Under regular wave condition, the coupling between the surge and pitch motions are not obvious because of the small amplitude of spar body motion; but under extreme condition, pitch motion may get about $20 \%$ smaller than that without consideration of the coupling between the surge and pitch motions.

\section{ACKNOWLEDGMENTS}

The authors of this paper would like to thank the financial supports provided by the National Natural Sciences Foundation (Grant No. 11232012 and 11372320).

\section{REFERENCES}

[1] Robertson A N, Jonkman J M. Loads analysis of several offshore floating wind turbine concepts[M]. National Renewable Energy Laboratory, US Department of Energy, Office of Energy Efficiency and Renewable Energy, 2011.

[2] Karimirad M, Moan T. Wave-and wind-induced dynamic response of a spar-type offshore wind turbine[J]. Journal of waterway, port, coastal, and ocean engineering, 2011, 138(1): 920.

[3] Fischer T, Kuhn M, Jonkman J. Model development and loads analysis of a wind turbine on a floating offshore tension leg platform[M]. National Renewable Energy Laboratory, 2010. [4] Jonkman J M. Dynamics modeling and loads analysis of an offshore floating wind turbine[M]. ProQuest, 2007.

[5] Browning J R, Jonkman J, Robertson A, et al. Calibration and validation of the FAST dynamic simulation tool for a spartype floating offshore wind turbine[C].Proc. 2012 Science of Making Torque from Wind Conference. 2012.

[6] Jonkman J M, Buhl Jr M L. Loads analysis of a floating offshore wind turbine using fully coupled simulation[C]. Wind Power Conference and Exhibition, Los Angeles, CA. 2007.

[7] Waris M B, Ishihara T. Dynamic response analysis of floating offshore wind turbine with different types of heave plates and mooring systems by using a fully nonlinear model[J]. Coupled Systems Mechanics, 2012, 1(3): 247-268.

[8] Sethuraman L, Venugopal V. Hydrodynamic response of a stepped-spar floating wind turbine: Numerical modelling and tank testing[J]. Renewable Energy. 2013, 52: 160-174.
[9] Masciola, M., Robertson, A., Jonkman, J., Coulling,A., Goupee,A., 2013. Assessment of the importance of mooring dynamics on the global response of the DeepC-Wind floating semisubmersible offshore wind turbine. In: Proceedings of the Twenty-third(2013) International Offshore and Polar Engineering Conference, Anchorage, Alaska, USA.

[10] Hall M, Goupee A. Validation of a lumped-mass mooring line model with DeepCwind semisubmersible model test data[J]. Ocean Engineering. 2015, 104: 590-603.

[11] Hall, M., Buckham, B., Crawford, C., 2014. Evaluating the importance of mooringline model fidelity in floating offshore wind turbine simulations. Wind Energy17, 1835-1853.

[12] Palm J, Paredes G M, Eskilsson C, et al.Simulation of mooring cable dynamics using a discontinuous Galerkin method. In: Proceedings of $\mathrm{V}$ International Conference on Computational Methods in Marine Engineering, Hamburg, Germany, 2013.

[13] Matha D, Bischoff O, Fechter U, et al. Non-linear multibody mooring system model for floating offshore wind turbines[J]. EWEA Offshore 2011, 2011.

[14] Skaare B, Hanson T D, Nielsen F G, et al. Integrated dynamic analysis of floating offshore wind turbines[C].2007 European Wind Energy Conference and Exhibition. 2007.

[15] Larsen T J, Hanson. A method to avoid negative damped low frequent tower vibrations for a floating, pitch controlled wind turbine[J]. Journal of Physics: Conference Series. 2007, 75: 12073.

[16] Kallesoe B S, Paulsen U S, Kohler A, et al. Aero-hydroelastic response of a floating platform supporting several wind turbines[C].49th AIAA aerospace sciences meeting. Orlando, Florida. 2011.

[17] Jeon S H, Cho Y U, Seo M W, et al. Dynamic response of floating substructure of spar-type offshore wind turbine with catenary mooring cables[J]. Ocean Engineering. 2013, 72: 356364.

[18] Christiansen S, Bak T, Knudsen T. Damping Wind and Wave Loads on a FloatingWind Turbine[J]. Energies. 2013, 6(8): 4097-4116.

[19] Stewart G. Calibration and Validation of a FAST Floating Wind Turbine Model of the DeepCwind Scaled Tension-Leg Platform: Preprint[J]. Office of Scientific \& Technical Information Technical Reports, 2012.

[20] Karimirad M. Modeling aspects of a floating wind turbine for coupled wave-wind-induced dynamic analyses[J]. Renewable Energy. 2013, 53: 299-305.

[21] Shin H, Pham T D, Jung K J, et al. Model test of new floating offshore wind turbine platforms $[\mathrm{J}]$. International Journal of Naval Architecture and Ocean Engineering. 2013, 5(2): 199-209.

[22] Kim B W, Sung H G, Kim J H, et al. Comparison of linear spring and nonlinear FEM methods in dynamic coupled analysis of floating structure and mooring system[J]. Journal of Fluids and Structures, 2013, 42: 205-227.

[23] Sagrilo L V S, Siqueira M Q, Ellwanger G B, et al. A coupled approach for dynamic analysis of CALM systems[J]. 
Applied ocean research, 2002, 24(1): 47-58.

[24] Chen X, Zhang J, Ma W. On dynamic coupling effects between a spar and its mooring lines[J]. Ocean Engineering, 2001, 28(7): 863-887.

[25] Van den Boom, H.J.J, Dynamic behaviour of mooring lines, Proceedings of BOSS'85 Behaviour of Offshore Structures, Delft, 359 368.

[26] Jonkman J M. Definition of the Floating System for Phase IV of OC3[M]. Golden, CO, USA: National Renewable Energy Laboratory, 2010.

[27] Jonkman J M, Butterfield S, Musial W, et al. Definition of a 5-MW reference wind turbine for offshore system development[M]. National Renewable Energy Laboratory Golden, CO, 2009. 